\title{
TALENTO ACADÊMICO E DESEMPENHO ESCOLAR: A IMPORTÂNCIA DA MOTIVAÇÃO NO CONTEXTO EDUCACIONAL
}

\author{
Izamara da Silva \\ Mestre em Psicologia pela UNIVERSO, \\ Marsyl Bulkool Mettrau \\ Profa Orientadora, Doutora em Educação pela Universidade do Minho.
}

\begin{abstract}
Resumo
A educação direcionada a alunos mais capazes e com características de superdotação ainda apresenta desafios. Os fatores relacionados ao desenvolvimento cognitivo e os programas de atendimento, têm sido objeto de crescente investigação entre os pesquisadores nesta área de estudos Guimarães (2007). Um dos desafios para os pesquisadores na área, é a relação entre motivação, inteligência e altas habilidades/ superdotação. Prestar atendimento adequado a estes alunos especiais, significa oferecer igualdade de oportunidade para o desenvolvimento de seu potencial. A excelência do ensino proposta em programas especiais para superdotados também deve ser considerada como uma prática democrática da educação, pois visa atender às necessidades individuais deste agrupamento. Participaram desta pesquisa 52 (cinqüenta e dois) estudantes de ensino médio da cidade do Rio de Janeiro, bolsistas de um Instituto Social. A presente pesquisa investiga os aspectos motivacionais intrínsecos e extrínsecos que indicam as estratégias usadas por estes estudantes para favorecer a manutenção dos traços da motivação. Como instrumento utilizou-se a Escala de Motivação Escolar para Alunos do Ensino Fundamental, desenvolvida por Manzini \& Martinelli (2006), cujas orientações motivacionais estão distribuídas em 31 questões, 15 referentes à motivação intrínseca e 16 referentes da motivação extrínseca. Os resultados obtidos apontam a motivação intrínseca como a principal característica motivacional presente nestes alunos e demonstram o quão envolvidos estão estes sujeitos nas tarefas as quais se propõem realizar ao longo do programa do Instituto Social Maria Telles. A média da motivação intrínseca obtida na aplicação da escala foi de superior $(18,2)$, em relação a média da motivação extrínseca $(13,8)$, também confirmando este resultado. Muito mais que atingir objetivos e alcançar metas em um Programa voltado para indivíduos com altas habilidades/ superdotação, estes estudantes têm como característica principal o prazer em estudar. Conhecer os aspectos motivacionais destes alunos auxilia na seleção de estratégias que, não somente ampliam os diferentes aspectos da motivação, mas permitem que esta se mantenha durante toda a execução das tarefas, favorecendo o alcance de resultados positivos e satisfatórios, criando um ambiente de satisfação e bem estar durante o desempenho escolar de cada um deles.
\end{abstract}

Palavras-chave: altas habilidades, talento acadêmico, motivação.

\section{ACADEMIC PERFORMANCE AND TALENT SCHOOL: THE IMPORTANCE OF MOTIVATION IN EDUCATION}

\begin{abstract}
The education aimed at more skilled students with traits of giftedness still poses challenges. Factors related to the cognitive development and counseling programs have been the object of growing interest among researchers in this field, such as Guimarães (2007). One of the challenges for them is the relation between motivation, intelligence and high abilities/giftedness. To provide adequate counseling to such special students means to offer them equal opportunities for the development of all their potentiality. The teaching excellence proposed in special programs for the gifted should also be considered as a democratic educational practice since they intend to
\end{abstract}


meet individual needs. Fifty-two high school students from Rio de Janeiro, scholarship holders of the Social Institut, took part in this research, which investigates intrinsic and extrinsic motivational aspects that indicate the strategies used by them to favor the maintenance of the motivational features. The means used was the Scholastic Motivation Scale for Junior High School Students (Escala de Motivação Escolar para Alunos do Ensino Fundamental), developed by Manzini \& Martinelli (2006), whose motivational guidance is arranged in 31 questions, 15 on intrinsic motivation and 16 on extrinsic ones. The results point out the intrinsic motivation as the main motivational feature present in these students and show how committed they are to the tasks they have pledged to perform throughout the Social Institut Maria Telles program. The average of the intrinsic motivation obtained from the use of the variable was superior (18.2) in relation to the extrinsic one (13.8), also verifying such result. More than achieving the objectives and attaining the goals in the program, these students have pleasure in studying as their main characteristic. Knowing the motivational aspects of these students helps the choice of strategies, which not only extends the different aspects of motivation but also allows it to be sustained during the performance of the tasks, favoring the achievement of positive and satisfactory results, creating a pleasant and healthy atmosphere during the fulfillment academic performance of each student.

Keywords: high abilities, talents academic, motivation.

\title{
RENDIMIENTO ACADÉMICO Y TALENTO ESCUELA: LA IMPORTANCIA DE LA MOTIVACIÓN EN LA EDUCACIÓN
}

\begin{abstract}
Resumen
La educación dirigida a los estudiantes más capaces y las características de superdotação también presenta desafíos. Factores relacionados con el desarrollo cognitivo y programas de atención, han sido objeto de investigación cada vez mayor entre los investigadores en este campo de estudio Guimarães (2007). Uno de los retos para los investigadores en el área, es la relación entre la motivación, la inteligencia y el alto nivel de capacitación / superdotação. Proporcionar la atención adecuada a estos estudiantes, esto significa brindar igualdad de oportunidades para desarrollar su potencial. La excelencia de la enseñanza propuesta sobre programas especiales para la super debe ser considerada como una práctica democrática de la educación, que tiene por objeto satisfacer las necesidades individuales de este grupo. Participaron en esta investigación 52 (cincuenta y dos) de los estudiantes de secundaria en Río de Janeiro, la población de un Sociales. Esta investigación estudia la motivación intrínseca y extrínseca aspectos indican que las estrategias utilizadas por los estudiantes para fomentar la conservación de los vestigios de la motivación. Como un instrumento utilizando una escala de Motivación de Estudiantes en la escuela primaria, desarrollado por Manzini y Martinelli (2006), las orientaciones motivacionales que se distribuyen en 31 puntos, 15 en la motivación intrínseca y 16 de la motivación extrínseca. Los resultados indican la motivación intrínseca como la característica clave de motivación en los estudiantes y mostrar cómo estos temas están involucrados en las tareas que realizará durante el programa del Instituto Social de María Telles. El promedio de motivación intrínseca de la aplicación de la escala era mayor $(18,2)$, la motivación extrínseca, en promedio $(13,8)$, también confirmó este resultado. Mucho más que el logro de metas y objetivos en un programa orientado a las personas con altas cualificaciones / superdotação, estos estudiantes tienen como característica principal el placer de estudio. Conoce a los aspectos de motivación de los estudiantes ayuda en la selección de estrategias que no sólo ampliar los diferentes aspectos de la motivación, pero este se mantenga a lo largo de las tareas, favoreciendo el logro de resultados positivos y las buenas, creando una atmósfera de satisfacción y bienestar para el rendimiento educativo de cada uno.
\end{abstract}

Palabras clave: alta cualificación, conocimientos académicos, la motivación. 


\section{INTRODUÇÃO}

Os estudos sobre a inteligência têm gerado nos diferentes grupos de profissionais e da própria opinião pública objeto de um largo número de investigação (Almeida, 1988). Através do registro histórico e através da pesquisa bibliográfica, a literatura destaca que a introdução do conceito de inteligência em psicologia, conforme cita Guedes (2005), remonta ao final do século XIX, com os filósofos ingleses Herbert Spencer e Francis Galton. Para ambos, a inteligência identifica-se com uma aptidão geral superposta a aptidões específicas. Ainda segundo Guedes (2005), Spearman partiu da constatação de que existem correlações positivas entre os diversos testes e para explicá-los admitiu a intervenção de um fator geral comum a todos e que atuaria ao lado de fatores específicos para cada teste. Ao estudar esse fator geral, Spearman identificou-o com uma espécie de energia geral ou mental. Podia-se comparar o funcionamento psíquico com o de máquinas, cujo acionamento correria por conta de uma fonte geradora de energia, que é o fator geral.

Segundo Virgolim (2007), a partir do trabalho pioneiro dos franceses Binet e Simon nos primeiros anos de século $X X$, as diferenças intelectuais entre as pessoas passaram a ser cientificamente estudadas e medidas. Binet elaborou, no início do século $X X$, um método que constava de uma série de perguntas bastante simples, que eram propostas às crianças. Os resultados obtidos de uma das crianças eram comparados aos produzidos pelas outras crianças da mesma faixa de idade. A técnica de Binet consistiu em partir da observação do que fazem os sujeitos mais bem dotados em relação à média dos indivíduos. Não partiu, portanto, de uma conceituação prévia do que pudesse ser a inteligência.

Para Virgolim (2007), Guilford foi um dos primeiros a propor que a inteligência deveria ser entendida como sendo multidimensional. Ele propôs por volta da metade do século passado, um modelo para se entender a estrutura do intelecto, que descrevia os diferentes tipos de capacidades cognitivas. Para ele as operações intelectuais poderiam ser a cognição, a memória, o pensamento convergente, o pensamento divergente e a avaliação.

Outro autor de grandes contribuições no campo de estudos da inteligência humana é Sternberg (2000) com a Teoria Triárquica: tri significa três e árquica significa governada. Segundo este autor, a inteligência compreende três aspectos e ressalta que os três aspectos tratam da relação da inteligência: com o mundo interno na pessoa, com a experiência e com o mundo externo. 
Sternberg (2000) considera a inteligência em uma relação contextual, isto é, num contexto do mundo real. Neste sentido, vincula a inteligência ao significado da vida cotidiana, na adaptação, modificação e seleção destes contextos, de forma organizada e planejada pelo sujeito. Considerar a inteligência em relação ao contexto social, em todo seu dinamismo, fez com que os teóricos vissem a necessidade de ampliar as abordagens em relação às medidas da inteligência. Desta forma, a inteligência sai dos laboratórios e entra no mundo real, seja este a escola ou o mundo de trabalho do adulto. Assim, a inteligência deixa de ser medida somente em testes de QI (quociente de inteligência), para buscar respostas inteligentes e solucionar problemas nas diferentes situações da vida cotidiana. A teoria de Sternberg é composta de três subteorias que são a base para explicar e compreender o que ele denominou a inteligência excepcional, a qual explica a natureza do funcionamento da inteligência extraordinária, especificando ainda, tipos de tarefas que estão mais ou menos próximas como a medida de talento intelectual.

Para Mettrau (1995), a inteligência significa algo que qualifica uma pessoa para resolver problemas corretamente, para se adaptar a situações novas e para aprender. A pesquisadora alerta, no entanto, que a inteligência não pode ser vista como algo independente da cultura, ou seja, cultura e inteligência estão interligadas permanentemente.

Mettrau (2000) ainda nos explica a inteligência como um processo dinâmico, sem hierarquia, chamando a atenção para a importância das diferentes expressões da inteligência no ser humano: o criar (criação), o sentir (emoção) e o conhecer (cognição).

Esta autora nos diz que, a maioria das pessoas, em suas variadas formações, níveis de conhecimento e classes sociais, demonstra, de maneira implícita ou explícita, que a inteligência é um valor. Sendo um valor, é algo em que as pessoas pensam, refletem e hierarquizam em sua ordem de valores pessoais. O conceito de inteligência segundo Mettrau (2000) foi abordado na perspectiva de patrimônio social, isto é, algo que deve ser cuidado, reconhecido e até tombado em alguns casos, pois o mundo caminha, se constrói e se destrói, através da inteligência das pessoas, principalmente através do modo como usam esta inteligência, que pode ser a favor ou contra todo o grupo social e contra si próprio. Segundo o ponto de vista desta autora, a inteligência deixa de ser somente individual para ser coletiva e, como tal, é um bem social, da 
propriedade de todos, devendo o seu uso ser encorajado e desenvolvido o mais plenamente possível.

Segundo Virgolim (2007), desde o século passado, áreas como a Psicologia e a Educação têm chamado a atenção para as necessidades especiais dos indivíduos com altas habilidades/superdotação. Mas é relativamente recente a criação de programas, serviços de atendimento, identificação e aconselhamento, para este grupo de pessoas.

Nos últimos 30 anos, conforme descreve Alencar \& Feith (2001), o interesse pela educação das pessoas que se destacam por um potencial promissor tem sido estudado e pesquisado por diferentes profissionais na área da Psicologia e da Educação além de outras. Inclusive muitos pesquisadores apontam para um crescimento nos investimentos em programa especiais de atendimento como conseqüência do progresso da ciência, da tecnologia, da competitividade e do reconhecimento de vantagens sociais e econômicas relacionadas ao desenvolvimento do potencial de indivíduos com habilidades superioras. Com isso os fatores educacionais relacionados aos comportamentos de superdotação tem sido, concomitantemente, objeto de investigação, uma vez que exercem forte influência sobre o desenvolvimento humano ao longo da vida.

Os profissionais da área da educação em geral costumam entender a inteligência em termos de critérios e resultados significativos em determinado grupo social. Assim, quando observamos pessoas com boa comunicabilidade, raciocínio rápido, habilidades para determinada tarefa, costumamos dizer e achar que tal pessoa é inteligente.

Mettrau (1995) afirma que só a partir da visão integrada do ser humano, podem-se compreender as chamadas manifestações inteligentes sem esquecer, é claro, da influência do afeto e do meio onde estas se manifestam e expressam. Assim os aspectos cognitivos, criativos e afetivos estarão sempre presentes na produção intelectual de uma pessoa. Pode-se observar a expressão da inteligência através do ato de criar e transformar a realidade.

As características encontradas neste tipo de estudantes mais citadas por estes autores acima são: curiosidade e vivacidade mental; motivação e energia; persistência na área de seu talento; facilidade de compreensão e percepção da realidade; capacidade de resolver problema; habilidade em assumir riscos; sensibilidade; pensamento original e divergente; conduta criativa. 
Dentre os pesquisadores que estudam o tema altas habilidades $\mathrm{e}$ superdotação um dos mais conceituados na atualidade é o americano Joseph Renzulli, que defende a idéia de que altas habilidades se refere a um aspecto situacional, isto é, o indivíduo que tem um potencial maior deve ter oportunidades para desenvolvê-lo. Neste sentido, Renzulli (1986) propõe uma definição de superdotação baseada na concepção dos três anéis, que sugere o entrelaçamento de três fatores: habilidade acima da média, envolvimento com a tarefa e criatividade. Cada um desses fatores exerce um papel importante na identificação de comportamentos superdotados.

Habilidade acima da média envolve habilidades gerais, que consistem na capacidade de processar informações, de integrar experiências que resultem em respostas apropriadas e adaptadas a novas situações, bem como habilidades específicas, que consistem na capacidade de adquirir conhecimento, prática e habilidades para atuar em uma ou mais atividades de uma área específica. Envolvimento com a tarefa refere-se à motivação, uma energia canalizada para uma tarefa em particular ou uma área específica, assim como perseverança, persistência, dedicação e autoconfiança.

O terceiro fator, criatividade, envolve fluência, flexibilidade e originalidade de pensamento, abertura a novas experiências, curiosidade, sensibilidade e coragem para correr riscos. É importante ressaltar que os três fatores não precisam estar interagindo ao mesmo tempo e nem na mesma intensidade, mas é necessário que interajam em algum grau para que possam resultar em um alto nível de produtividade.

A avaliação e a identificação do estudante com altas habilidades/ superdotação e o melhor conhecimento de suas características, contribuem para o entendimento de como é constituída e de como se desenvolve a motivação destas pessoas no cotidiano e no ambiente acadêmico.

Sobre a motivação no contexto escolar, Boruchovitch (2002) descreve que a motivação para a aprendizagem está sendo definida como a iniciação e manutenção de comportamento com o objetivo de se atingir uma determinada meta. Para que isso aconteça o aluno precisa enfrentar tarefas desafiadoras, com empenho e perseverança bem como deve empregar estratégias de aprendizagem. Além disso, o professor deve propiciar um clima de sala de aula favorável ao desenvolvimento das orientações motivacionais. 
Para tanto é necessário compreender como se desenvolve a motivação no indivíduo, mais precisamente nos indivíduos com altas habilidades/ superdotação, para suas realizações pessoais. Deste modo, como cita Bzuneck (2004), a motivação acaba sendo uma questão chave no âmbito da educação. Este autor cita que alunos desmotivados estudam muito pouco ou nada e, conseqüentemente, quase sempre aprendem muito pouco.

As pesquisas desenvolvidas nos anos 80, segundo Bzuneck (2004) buscavam encontrar respostas para alguns problemas tais como formas de auxiliar alunos a terminar os trabalhos iniciados, facilitar o desenvolvimento de novas habilidades e de emoções positivas em relação à aprendizagem, melhorar a qualidade dos trabalhos escolares, entre outras. No entanto, quando se pensa em motivação para a aprendizagem é preciso considerar as características do ambiente escolar. De forma geral, as tarefas e atividades proporcionadas no ambiente escolar estão relacionadas a processos cognitivos como: capacidade de atenção, concentração, processamento de informações, raciocínio e resolução de problemas. Devido a estas características, Bzuneck (2004) acredita que aplicar conceitos gerais sobre motivação humana no ambiente escolar não seria muito apropriado sem a consideração das singularidades deste ambiente. Assim, a motivação pode influenciar no modo como o aluno utiliza suas capacidades além de afetar na percepção, atenção comportamento social, emocional, aprendizagem e desempenho.

Ao longo dos anos, algumas teorias foram estudadas a fim de tratar da motivação: (a) a abordagem comportamental da motivação pode ser identificada principalmente em Skinner em sua obra mais célebre do behaviorismo intitulada "O mito da Liberdade". Ali o autor trabalhou com a conduta em termos de reforços positivos (recompensas) contra reforços negativos (castigos). Sua teoria baseia-se na idéia de que o aprendizado ocorre em função de mudança no comportamento manifesto. As mudanças no comportamento são o resultado de uma resposta individual a eventos (estímulos) que ocorrem no meio. Portanto, na abordagem comportamental, o professor pode orientar o processo de motivação dos seus alunos por meios de recompensas externas, incentivos e punições Bergamini (1990). Trata-se de uma abordagem baseada na reação de grupos de alunos a ações provocadas em seu cotidiano escolar, de forma a levar o aprendiz a responder positivamente ao planejamento educacional oferecido. 
Quando se pensa em motivação para a aprendizagem é preciso considerar as características do ambiente escolar. De forma geral, as tarefas e atividades proporcionadas no ambiente escolar estão relacionadas a processos cognitivos como: capacidade de atenção, concentração, processamento de informações, raciocínios e resolução de problemas.

Neste sentido, Bzuneck (2004) diz que, a partir do século XX, vem sendo desenvolvida uma abordagem cognitivista da motivação, tendo como pressuposto central que o comportamento de uma pessoa é iniciado e regulado pelo seu pensamento, expectativas e atribuições e não por eventos ou condições físicas. Segundo este mesmo autor, toda pessoa dispõe de recursos pessoais como o tempo, a energia, os talentos, os conhecimentos e as habilidades.

Tais recursos poderão ser investidos em qualquer atividade escolhida pelo indivíduo, sendo mantidos, enquanto estiverem atuando os fatores motivacionais. Desta forma, a motivação pode influenciar no modo como o indivíduo utiliza suas capacidades, além de afetar sua percepção, atenção, memória, pensamento, comportamento social, emocional, aprendizagem e desempenho.

Duas pesquisas citadas por Bzuneck (2004), a de Costa e de Martini, foram realizadas nos últimos anos, por educadores e psicólogos, sobre a motivação do aluno no contexto escolar. As cognições humanas, tais como crenças, pensamentos, expectativas e sentimentos relacionados ao processo de aprender têm sido objeto de estudo das teorias sócio-cognitivas da motivação para a aprendizagem. As abordagens sócio-cognitivistas da motivação têm demonstrado a existência de duas orientações motivacionais: a intrínseca e a extrínseca. A motivação intrínseca configura-se como uma tendência natural da pessoa buscar novidades e desafios. O indivíduo realiza determinada atividade pela própria causa, por considerá-la interessante, atraente ou geradora de satisfação. É uma orientação motivacional que tem por característica a autonomia do aluno e a auto-regulação de sua aprendizagem.

A motivação extrínseca, segundo Amabile (1994), tem sido definida como a motivação para trabalhar em resposta a algo externo à tarefa, como a obtenção de recompensas externas, materiais ou sociais, em geral, com a finalidade de atender solicitações ou pressões de outras pessoas ou de demonstrar competências e habilidades. Guimarães (2001) afirma que de acordo com as pesquisas no contexto escolar há indicadores de que a motivação intrínseca 
facilita a aprendizagem e o desempenho dos estudantes. $O$ aluno intrinsecamente motivado envolve-se em atividades que oferecem a oportunidade para o aprimoramento de seus conhecimentos e de suas habilidades. Por sua vez, o indivíduo extrinsecamente motivado, realiza uma tarefa escolar para melhorar suas notas ou para conseguir prêmios e elogios dos professores.

Os aspectos motivacionais dizem respeito às forças impulsionadoras da performance criativa (Guimarães, 2001). Esta autora ainda nos diz que especialmente a motivação intrínseca, centrada na tarefa, é de inestimável importância para os estudos da inteligência e da criatividade, uma vez que as pessoas estão muito mais propensas a responder criativamente a uma dada tarefa quando estão movidas pelo prazer de realizá-la. Em síntese, pode-se dizer que a motivação para a aprendizagem vem sendo entendida pelos teóricos contemporâneos como um constructo multidimensional caracterizado por teorias pessoais, atribuição de causalidade, orientações motivacionais intrínsecas e extrínsecas, conforme descreve Boruchovitch (2001).

Tal aspecto foi observado em vários estudos revistos por Sternberg (2000) com profissionais que vinham realizando trabalhos altamente criativos em distintas áreas e que se diziam mobilizadas pelo amor à tarefa, focalizando muito mais sua atenção e energia no trabalho em si do que em possíveis prêmios ou reconhecimento por sua realização. Consideram, entretanto, que ambos os tipos de motivação: intrínseca e extrínseca, estão freqüentemente em interação, combinando-se mutuamente para fortalecer a criatividade.

Amabile (1996), que também estuda os diferentes aspectos da motivação, orienta parte de seus estudos aos fatores relacionados à motivação intrínseca e a criatividade. Segundo esta autora, motivação intrínseca refere-se à satisfação e ao envolvimento que o indivíduo demonstra pela tarefa, independente de reforços externos, e engloba interesse, competência e autodeterminação. Provavelmente um indivíduo vai se sentir mais motivado quando a atividade captura seu interesse; é desafiadora, leva-o a desenvolver sentimentos de autoeficácia e envolvimento com a atividade por conta própria. Assim a motivação pode levar o indivíduo a buscar mais informações sobre a área estudada e, conseqüentemente, desenvolver mais as suas habilidades de domínio. Da mesma maneira, altos níveis de motivação podem levar o indivíduo a se arriscar e a romper com estilos de produção de idéias habitualmente empregados, 
contribuindo para o desenvolvimento de novas estratégias criativas Amabile (1994).

Por outro lado, a motivação extrínseca pode minar, em parte, o processo criativo. Motivação extrínseca descrita por Amabile (1996), diz respeito ao envolvimento do indivíduo em uma tarefa com o objetivo de alcançar alguma meta externa à tarefa e é marcada pela recompensa e reconhecimento externos.

Sendo assim, a presente pesquisa procurou inserir o estudo das altas habilidades e talento sob a perspectiva da motivação escolar. No intuito de contribuir mais ainda para a compreensão sobre este indivíduo e seus níveis de motivação, propôs-se um estudo com 52 jovens de Ensino Médio,com características de altas habilidades/ superdotação, na cidade do Rio de Janeiro e participantes de um Instituto Social Maria Telles que busca dar atendimento e assistência a alunos identificados como talento acadêmico e/ ou altas habilidades/ superdotação.

Esta pesquisa tem como objetivo geral, verificar os níveis de motivação do estudante de ensino médio e com talento acadêmico. Como objetivo específico busca verificar quais aspectos motivacionais, intrínsecos e extrínsecos, influenciam nas estratégias usadas por estes estudantes, para favorecer a manutenção destes traços da motivação.

\section{MÉTODO}

\section{Participantes}

A amostra utilizada para recorte metodológico foi composta por um grupo de alunos identificados com talento acadêmico, acompanhados através de um projeto voltado ao seu atendimento específico, realizado em um Instituto Social, no Rio de Janeiro. Dentre os 196 alunos deste Instituto, convidamos todos os 70 estudantes que cursam o ensino médio. Destes 70 estudantes convidados, 52 aceitaram participar da pesquisa e o critério utilizado foi o fato de todos os participantes estarem cursando o Ensino Médio. Dos 52 participantes desta pesquisa, 14 destes são meninas e 38 são meninos, com idades entre 14-16 anos. Todos os participantes são egressos de escolas municipais e atualmente matriculados em escolas particulares de primeira linha do município do Rio de Janeiro, que recebem apoio deste Instituto para auxiliar seus estudos acadêmicos. O apoio é estendido às seguintes áreas: pagamento das mensalidades escolares, alimentação, transporte, material escolar, apoio 
pedagógico e psicopedagógico quando necessário e atividades extracurriculares (passeios, cursos de línguas, excursões e outros).

\section{Instrumentos}

Esta pesquisa utilizou a Escala de Motivação Escolar para Alunos do Ensino Fundamental (Manzini, 2006), a qual foi adaptada, sob a orientação da própria Martinelli autora da mesma, para alunos do Ensino Médio. Para tal utilização fezse contato com as pesquisadoras que nesta ocasião discutiram a melhor forma para que a aplicação e utilização do instrumento.

$\mathrm{Na}$ escala, cada questão apresenta três alternativas as quais foram pontuadas da seguinte forma: (a) para as respostas Sempre: atribuídos 2 pontos; (b) para as respostas Às vezes: atribuído 1 ponto; e (c) para as respostas Nunca, atribuído 0 pontos. Para análise dos dados quantitativos e qualitativos desta escala, realizamos uma análise comparativa entre os níveis de motivação intrínseca e extrínseca, apresentados nas respostas da Escala de Motivação utilizada de acordo com as dimensões das respectivas questões.

Seguindo a orientação da literatura especializada na área da motivação, altas habilidades/superdotação e a partir dos estudos de Manzini (2006), a escala de motivação escolar foi construída para medir cinco dimensões referentes à motivação intrínseca (MI) e cinco referentes à motivação extrínseca (ME). Para a motivação intrínseca têm-se as seguintes dimensões e suas respectivas questões: (a) autodeterminação nas questões $(8,12,13)$; (b) competência nas questões $(3,17,20,27)$; (c) envolvimento com a tarefa na questão (21); (d) curiosidade nas questões $(1,7,14)$ e (e) interesse nas questões $(2,9,28)$. Para a motivação extrínseca, as dimensões e questões utilizadas foram: (a) preocupação com avaliação nas questões $(10,19,22,24)$; (b) preocupação com reconhecimento nas questões $(4,6,16,18)$; (c) preocupação com competição nas questões $(15,26)$; (d) enfoque no dinheiro ou outro incentivo claro nas questões $(11,29)$; (e) enfoque na preocupação com os outros na questão (5).

\section{Procedimento}

Optou-se pelo uso de uma metodologia quantitativa e, quando necessário, as análises de alguns aspectos qualitativos foram abordados. Justifica-se tal escolha dentro do contexto escolar destes alunos talentosos, buscando respostas 
objetivas para a compreensão dos processos que envolvem as questões voltadas para os aspectos relacionados à motivação.

Como instrumento de coleta de dados utilizou-se a Escala de Motivação Escolar para Alunos do Ensino Fundamental, desenvolvida por Manzini (2006). Através deste instrumento de coleta de dados voltou-se para a identificação de características objetivas do aluno com talento acadêmico em seu processo de aprendizagem, no âmbito da adolescência, faixa estaria esta que ainda temos poucos estudos abrangendo este tipo de aluno.

A aplicação foi realizada em grupos, uma vez que as reconhecidas habilidades deste grupo de sujeitos favorecem esta modalidade de intervenção e o modelo do próprio instrumento também. Para a definição das variáveis, sendo nosso objeto a motivação, como uma categoria atitudinal, utilizou-se de um instrumento validado pelas autoras acima citadas. Trata-se das variáveis de motivação intrínseca e extrínseca arroladas na Escala de Motivação Escolar de Alunos do Ensino Fundamental, desenvolvida pelas autoras. Estas variáveis contemplam categorias indissociáveis do processo motivacional no âmbito educacional tais como: sala de aula; empenho do aluno, satisfação em ir à escola; de independência nas tarefas curriculares descritas nas questões da escala.

\section{DISCUSSÃO DOS RESULTADOS}

Os resultados obtidos possibilitaram um conhecimento mais apurado acerca das orientações motivacionais dos alunos e da análise sobre a correlação entre motivação intrínseca e extrínseca conforme é nossa proposta na realização desta pesquisa. Nesta análise, verificou-se a importância da motivação intrínseca nos diferentes níveis de desempenho escolar, bem como nas relações voltadas para o envolvimento com a tarefa e o alcance de objetivos propostos pelo Instituto.

Os resultados mostraram que a motivação intrínseca é bem maior que a motivação extrínseca neste grupo de estudantes. As estratégias de maior impacto estão evidentes nas questões que envolvem a dimensão autodeterminação e envolvimento com a tarefa, pelos escores mais altos apresentados.

Na escala de motivação a pontuação pode variar de 0 a 28 pontos para a motivação intrínseca e de 0 a 28 pontos para a motivação extrínseca. Os resultados apresentados indicam que, para a motivação intrínseca, a pontuação 
obtida foi entre 13 e 26 pontos, com média de 18,2. Pode-se constatar que a média encontrada entre os participantes se mostrou acima dos 14 pontos, revelando que a motivação intrínseca esteve superior à média da escala. Este é outro dado que nos faz constatar a motivação intrínseca superior a extrínseca.

Para a motivação extrínseca a pontuação obtida foi entre 7 e 22 pontos, com média de 13,8. Pode-se constatar que a média encontrada entre os participantes se mostrou abaixo dos 14 pontos, revelando que a motivação extrínseca é menos significativa nas respostas dos estudantes, conforme a Tabela 1.

Tabela 1.

Média em relação a Motivação Intrínseca e a Motivação Extrínseca.

\begin{tabular}{lcccc}
\hline \multicolumn{1}{c}{$\begin{array}{c}\text { Tipo de } \\
\text { motivação }\end{array}$} & Participantes & $\begin{array}{c}\text { Pontos } \\
\text { mínimos }\end{array}$ & $\begin{array}{c}\text { Pontos } \\
\text { máximos }\end{array}$ & $\begin{array}{c}\text { Média de } \\
\text { pontos obtidos }\end{array}$ \\
\hline $\begin{array}{l}\text { (MI) } \\
\text { Motivação }\end{array}$ & 52 & 13 & 26 & 18,2 \\
$\begin{array}{l}\text { Intrínseca } \\
\text { (ME) }\end{array}$ & & & & \\
$\begin{array}{l}\text { Motivação } \\
\text { Extrínseca }\end{array}$ & 52 & 7 & 22 & 13,8 \\
\hline
\end{tabular}

Tal resultado mostra quão relacionada está a motivação intrínseca no que se refere às características dos sujeitos com altas habilidades, apresentadas pelas autoras Mettrau (2000) e Virgolim (2007) referenciadas nesta pesquisa. Especialmente Renzulli (1994) apresenta o envolvimento com a tarefa, como um dos comportamentos observáveis através da demonstração de expressivo interesse, motivação e empenho pessoal nas tarefas que o aluno com altas habilidades realiza conforme já citado.

São apresentados os resultados a partir das 05 dimensões referentes à motivação intrínseca, presentes no instrumento utilizado. A primeira dimensão é a autodeterminação e, nesta pesquisa, mostrou que $59,6 \%$ dos participantes atribuem a autodeterminação como uma forte característica de suas orientações motivacionais, visto que marcaram a resposta sempre, para as alternativas propostas nestes itens. Nas questões indicadas $(8,12,13)$, nota-se uma diferença bastante significativa no resultado total de respostas marcadas, lembrando que foram atribuídos dois pontos nesta opção sempre. Ou seja, estes alunos revelaram uma autodeterminação bastante elevada, influenciando suas estratégias na manutenção da motivação. 
A segunda dimensão é a competência e, nesta pesquisa, mostrou que $78,8 \%$ dos participantes atribuem à competência deles uma forte característica de suas orientações motivacionais, visto que marcaram a opção às vezes para estas alternativas. Apenas $11,5 \%$ dos participantes atribuem à competência como sempre uma característica de suas orientações motivacionais. Vimos aqui que $11 \%$ é um índice baixo. Apenas $11 \%$ dos estudantes desta amostra julgam competentes para estudar e vencer os desafios que Ihes são oferecidos neste programa.

A terceira dimensão é o envolvimento com a tarefa e, nesta pesquisa, mostrou que $71,15 \%$ dos participantes escolheram sempre para a dimensão envolvimento com a tarefa. O envolvimento com a tarefa é um dos comportamentos, segundo a teoria dos três anéis de Renzulli (1994), adotada neste estudo como referência teórica para conceituar os alunos. Ora, este autor diz que o envolvimento com a tarefa refere-se à persistência e ao expressivo interesse que o sujeito apresenta em relação a uma determinada tarefa, problema ou área específica do desempenho e que caracteriza especialmente pela motivação e empenho pessoal (Renzulli, 1994). Estes alunos demonstraram na questão no 21, a alta capacidade de concentração e a motivação pelas tarefas acadêmicas. Ainda seguindo o modelo proposto por Renzulli, o envolvimento com a tarefa, diz respeito à motivação na execução da atividade ou resolução de um problema.

A quarta dimensão é a curiosidade que, nesta pesquisa, mostrou que $61,5 \%$ dos participantes apresentam traços de curiosidade respondendo as questões referentes a essa dimensão. Segundo Mettrau (1995) estudantes com altas habilidades apresentam traços como curiosidade e vivacidade mental. Ora, $61,5 \%$ dos estudantes desta pesquisa usam esta característica no favorecimento da manutenção de sua motivação.

Virgolim (2007) nos diz que o estudante superdotado do tipo acadêmico, tem necessidade de saber sempre mais e busca ativamente novas aprendizagens. Também se observa, neste tipo de aluno, a paixão por aprender, assim como a curiosidade e o interesse.

A quinta dimensão da motivação intrínseca é o interesse e, nesta pesquisa, mostrou que os participantes se apresentam interessados nas atividades escolares. Apenas 5,7\% indicam pouco interesse pelas atividades escolares. 
A seguir serão apresentados os resultados a partir das 05 dimensões referentes à motivação extrínseca, presentes no instrumento utilizado. A primeira dimensão é a preocupação com a avaliação, presente nas questões de número 10, 19, 22 e 24 e 86\% dos estudantes da pesquisa levam a sério o sistema de avaliação dos colégios onde estão matriculados. Ou seja não basta o talento que na área acadêmica. É preciso uma preparação, um estudo contínuo para darem conta da maratona de testes, provas e trabalhos que compõem o sistema de avaliação destes colégios.

A segunda dimensão é a preocupação com o reconhecimento, presentes nas questões 04, 06, 16 e 18. Dos participantes da pesquisa $77 \%$ se preocupam com o reconhecimento. Isso está muito claro na questão de número 16 onde eles responderam, que sempre tentam ir bem na escola para agradar aos pais e os professores.

A terceira dimensão é a preocupação com a competição presente nas questões de número, 15 e 26. As questões levantadas nesta dimensão estão ligadas ao esforço contínuo e a necessidade de ser o melhor da classe a fim de obterem os melhores resultados escolares e $67 \%$ dos estudantes demonstraram que se preocupam com a competição. Há um forte espírito de competição saudável neste grupo, no sentido de uma busca constante de melhoria dos resultados.

A quarta dimensão é o enfoque no incentivo presentes nas questões $11 \mathrm{e}$ 29. Dos participantes $82 \%$ responderam que nunca precisam de incentivo externo para fazerem os trabalhos escolares, esta constatação está presente na questão de número 29. Ou seja, a motivação intrínseca e o prazer em estudar é uma forte marca nos sujeitos da pesquisa, inclusive representada ma média entre as duas motivações.

A quinta e última dimensão neste aspecto, é a preocupação com os outros presentes nas questões 05, 23 e 27. Esta dimensão apontou que 89\% dos estudantes se preocupam com os outros, no sentido de ser generoso e cooperativo, que é um dos traços fortes dos alunos com altas habilidades. A realização pessoal dos estudantes passa pela questão da responsabilidade social no sentido de dar contribuição para os que precisam tanto no âmbito familiar quanto no escolar. Daí o resultado tão alto para esta dimensão. Importante ressaltar que o mercado de trabalho já exige a cooperação e o trabalho em equipe como no perfil das pessoas para ocuparem os cargos atuais. 
Pudemos observar os níveis de motivação intrínseca acima da média demonstram quão envolvidos estão estes sujeitos com as tarefas que realizam, os altos níveis de resultados acadêmicos obtidos ao longo do Programa, apresentam também criatividade na forma como realizam as tarefas propostas.

Muito além de atingir objetivos e alcançar metas em um Programa voltado para alunos com altas habilidades/superdotação, os participantes têm como característica principal o prazer em realizar as tarefas, além do dinamismo com que as executam. O esforço e o empenho para acompanhar as exigências destes colégios particulares que estudam são infinitamente maiores para os alunos do Instituto, pois precisam suprir as lacunas que trazem do sistema público de onde fizeram o ensino fundamental e também alguns aspectos socioculturais que se apresentam reduzidos.

No entanto o que se viu no resultado foi um alto nível de persistência, perseverança e motivação com os estudos, o que faz acreditar ainda mais que a Instituição está no caminho certo em apoiar estes jovens estudantes em suas habilidades e potenciais. São bem definidos os modos de pensar e as reações de comportamento de um aluno tipicamente voltado à meta de aprender. Alunos com esta orientação entendem que o sucesso nas realizações escolares consiste na melhoria em conhecimentos e habilidades e em progredir com inovação e criatividade.

Como relata Bzuneck (2004) estes alunos enfrentam desafios acadêmicos, que por seu grau de exigência, são vistos como capazes de fazê-los crescer intelectualmente. Os estudantes desta pesquisa mostraram o quanto estão dispostos a enfrentar as barreiras para superar metas estabelecidas por eles próprios.

\section{CONSIDERAÇÕES FINAIS}

Alunos desmotivados estudam muito pouco ou nada e, consequentemente, aprendem menos. Segundo Bzuneck (2004) em última instância, aí se configura uma situação educacional que impede a formação de indivíduos mais competentes para exercerem a sua cidadania e realizarem-se como pessoas, além de se capacitarem a aprender pela vida afora.

O sucesso no desenvolvimento da aprendizagem dos alunos está totalmente relacionado à motivação para aprender. O aluno motivado busca novos conhecimentos e oportunidades, mostrando-se envolvido com o processo de 
aprendizagem, participando continuamente das tarefas com entusiasmo e disposição para novos desafios, mesmo quando isso lhe custa muitas horas de empenho nas atividades. A motivação é um compromisso fundamental para facilitar a execução de programas voltados para a Educação Especial em geral que faz com que os alunos venham a se envolver prazerosamente no processo de aprendizagem.

No momento em que se reflete sobre questões que envolvem os portadores de altas habilidades percebe-se que estas pessoas, por inúmeras vezes, recebem rótulos inadequados $e$, muito em conseqüência disso algumas de suas necessidades não são atendidas. Ao escolher o tema desta pesquisa nota-se que se faz uma reflexão para a necessidade de analisar aspectos referentes aos estudantes sob o ponto de vista dos próprios sujeitos.

$\mathrm{Na}$ prática com estes estudantes percebe-se que alunos motivados não estão preocupados apenas com os resultados finais, mas com todo o dinamismo que se realiza em todo o processo em que está envolvido. Isto é muito importante no caso do programa onde estão inseridos.

Os resultados obtidos nesta pesquisa mostraram que as orientações motivacionais se relacionaram, mas que a motivação intrínseca sobrepõe a motivação extrínseca, neste grupo de estudantes. O ensino oferecido nos bons colégios particulares, onde estes estudantes estão matriculados e a utilização adequada de estratégias de aprendizagem, tem contribuído para ajudar estes alunos a manter o nível de sua motivação intrínseca.

No contexto acadêmico, um aluno motiva-se a envolver-se nas atividades de aprendizagem caso acredite que, com seus conhecimentos, talentos e habilidades, poderá adquirir novos conhecimentos, dominar um conteúdo, melhorar sua habilidade etc. Contudo como descreve Mettrau (1995) nem todo adolescente que apresenta altas habilidades e talentos tem que, obrigatoriamente, ser excelente em tudo que realiza.

Considerando um tema altamente relevante pela sua complexidade nas duas dimensões: motivação e superdotação, percebe-se que muito estudo se faz necessário para sanar todos os questionamentos existentes. Os resultados encontrados na presente pesquisa não podem, como se sabe, ser considerados conclusivos e também, não podem ser generalizados para todos os alunos com talento acadêmico. 
Alguns questionamentos tais como modelos de programas para o atendimento, o envolvimento e o apoio dado à família deste estudante, a indicação do aluno com altas habilidades, devem ser levantados para que futuras pesquisas possam ser realizadas, propiciando, também, aos profissionais desta área conhecimentos baseados em dados cientificamente comprovados.

Ressalta-se ainda, a necessidade de outras pesquisas na área e também que futuros estudos possam ser conduzidos com a finalidade de investigar as possíveis relações entre as variáveis motivacionais e o desempenho acadêmico dos estudantes com altas habilidade, visto que esse tema pode trazer grandes contribuições para os profissionais que lidam nos programas de atendimento ao estudante com talento acadêmico ampliando aspectos facilitadores para a implementação de Políticas Públicas.

\section{REFERÊNCIAS}

Alencar, E. S., \& Fleith, D.S. (2001). Superdotados: Determinantes, educação e ajustamento. São Paulo: E. P. U.

Almeida, L. S. (1988). Teorias da inteligência. Porto: Edições Psicologia.

Amabile, T. M. (1994). Growing up creative. Buffalo, NY: The Creative Education Foundation Press.

Amabile, T. M. (1996). The social psychology of creativity. New York: Springer.

Bergamini, C. W. (1990). Motivação, mitos e mal entendidos. São Paulo: Revista RAE, abril/junho.

Boruchovitch, E., \& Bzuneck, J. A. (2001). A motivação do aluno: Contribuições da psicologia contemporânea. Petrópolis: Ed. Vozes.

Guedes, R. F. N. (2005). Educação e autonomia: O momento de tomar decisões. Dissertação de Mestrado Não Publicada, Programa de Mestrado Profissionalizante em Ensino de Ciências da Saúde e do Ambiente, Centro Universitário Plínio Leite, Niterói.

Guimarães, T. G. (2007). Altas habilidades e desenvolvimento intelectual. In: Feltih, D. S., \& Alencar, E. M. L. S. Desenvolvimento de talentos e altas habilidades: Orientação a pais e professores. Porto Alegre: Ed. Artmed.

Guimarães, S. E. R. (2001). Necessidade de pertencer: Um motivo humano fundamental. In: Boruchocvitch, E., \& Bzuneck, A. (Org.). Aprendizagem: processos psicológicos e o contexto social na escola. Petrópolis: Ed. Vozes. 
Manzini, C. (2006). Motivação no contexto escolar e desempenho acadêmico. Dissertação de Mestrado Publicada, Programa de Mestrado da Universidade Estadual de Campinas, UNICAMP, Campinas.

Mettrau, M. B. (1995). Nos bastidores da inteligência. Rio de Janeiro: UERJ.

Mettrau, M. B. (2000). A representação social da inteligência e os portadores de altas habilidades. In: Mettrau, M. B. (Org). Inteligência: patrimônio social. Rio de Janeiro: Dunya.

Renzulli, J. S. (1986). The three-ring conception of giftdness: A developmental model for creative productivity. Em R. J. Sternberg \& J. E. Davis (Eds.), Conception of giftedness. New York: Cambridge University Press.

Renzulli, J. S. (1994) Desarrollo del talento en las escuelas; programa práctico para el total rendimiento escolar mediante el modelo de enriquecimiento escolar. In: Mate, Y. B. (Org.). Intervención e investigación psicoeducativas em alunos superdotados. Salamanca: Ed. Amarú.

Sternberg, R. J. Psicologia cognitiva. Porto Alegre: Artmed.

Virgolim, A. M. R. (2007). Altas habilidades e desenvolvimento intelectual. In: Feltih, D. S., \& Alencar, E. M. L. S. Desenvolvimento de talentos e altas habilidades: Orientação a pais e professores. Porto Alegre: Ed. Artmed.

Contato: marsyl@superig.com.br, izamara.silva@rj.ismart.org.br

Recebido em: 20/10/2010

Revisado em: 29/11/2010

Aceito em: 13/12/2010 